\title{
Compressive Strength Prediction of Roller-compacted Concrete Using Nondestructive Tests through Artificial Intelligence
}

\author{
Mohammad Ali HADIANFARD \\ Department of Civil and Environmental Engineering \\ Shiraz University of Technology \\ Shiraz, Iran \\ e-mail: hadianfard@sutech.ac.ir
}

\author{
Ali Reza NIKMOHAMMADI \\ Department of Civil and Environmental Engineering \\ Shiraz University of Technology \\ Shiraz, Iran \\ e-mail: nikmohammadi.alireza@gmail.com
}

\begin{abstract}
Roller-Compacted Concrete (RCC) is a type of concrete that has similar basic ingredients to conventional concrete but contains much less water and is known as nonslump concrete. Nondestructive testing (NDT) is a very good choice to evaluate the quality and strength of such concretes as RCC. These testes are easy, fast and efficient and are also of low cost. The aim of this study is estimation of compressive strength of RCC by offering suitable mathematical formulations based on results of nondestructive tests. For this purpose, many samples of RCC with and without fibers are made and tested by concrete breaking machines and nondestructive techniques including Schmidt hammer and ultrasonic tests. Finally, by the aid of Artificial Intelligence (AI) concepts, and using the values from nondestructive and destructive testes suitable relations were found. In practical projects by doing nondestructive tests and without performing destructive testes, the RCC compressive strength can be calculated from the proposed relations with high accuracy. If both Schmidt hammer and ultrasonic tests are used simultaneously, the accuracy increases.
\end{abstract}

Keywords-roller-compacted concrete; nondestructive test; Schmidt hammer; ultrasonic test; artificial intelligence

\section{INTRODUCTION}

Such nondestructive tests (NDT) as ultrasonic pulse velocity (UPV) and Schmidt hammer techniques are very effective measures to evaluate the quality and strength of concrete in existing buildings. These testes are fast and easy to perform and are of low cost. Therefore, such techniques are considered by many engineers and researchers to assess the strength and condition of concretes [1-5].

In general, there is no meaningful physical relationship between characteristics of concrete and what the NDT shows. Therefore, using these methods in the evaluation of the desired characteristics of concrete (especially compressive strength) is faced with some errors and they need to be supplied with calibration graphs for every kind of concrete. Manufacturers of these devices often propose empirical relationships for their tests. Many of these relationships are not suitable for all types of concretes and require some modifications. For this purpose, the use of mathematical and evolutionary models such as fuzzy logic, neural networks, artificial intelligence and genetic algorithm which can be managed based on empirical studies have been developed [6-8].
Roller Compacted Concrete (RCC) is a type of concrete that takes its name from the construction method used to build it. It is placed with conventional asphalt paving equipment, then compacted using steel-drum or rubber-tired rollers. Similar to conventional concrete, RCC consists of Portland cement, coarse and fine aggregates, and water. It, however, contains much less water and is known as zero slump concrete. Compaction is the most important step in RCC construction because it provides strength, density and surface texture. According to importance and application of RCC in pavements, dams and other constructions, many researchers investigated properties and strength of this type of concrete [9-11].

This study proposes some models to predict the compressive strength of RCC using ultrasonic pulse velocity (UPV) and Schmidt hammer techniques. For this purpose, many samples of RCC with and without fiber are made and tested. Then, important factors affecting the test results are studied, and finally Artificial Intelligence (AI) concepts are used for prediction of concrete strength. The proposed relationships are accurate, simple and easy to use and they are applicable for evaluating the compressive strength of $\mathrm{RCC}$ in the existing projects. The main focus of this research is employing combined NDT techniques to provide an accurate assessment of concrete compressive strength. The data from ultrasonic pulse velocity and Schmidt hammer tests are used simultaneously to calculate the strength of the existing roller compacted concrete.

\section{MATERIAL PROPERTIES AND MiX DESIGN}

To estimate the compressive strength of RCC based on results from nondestructive tests, three types of RCC were prepared and cast into $15^{*} 15 \mathrm{~cm}$ cubes. The first type of RCC was without fiber and was named Type A. In the second type, $1 \mathrm{~kg}$ of polypropylene (PP) fiber was used in $1 \mathrm{~m} 3$ of concrete and was named as Type B. The third type was consisted $2 \mathrm{~kg}$ of PP fiber in $1 \mathrm{~m} 3$ of concrete and was named Type C. The PP fibers had white color with $10 \mathrm{~mm}$ length. Also, three different sizes of coarse aggregates (gravel) were used in each of $\mathrm{A}, \mathrm{B}$ and $\mathrm{C}$ concretes. The maximum sizes of aggregates (MSA) for these three types of gravels were $12.5,19$ and $25 \mathrm{~mm}$, respectively.

In this study, 108 concrete samples were prepared and tested. For each concrete type (A, B and C) 36 samples were prepared including 12 different mix designs and 3 specimens 
in each mix design. All specimens after 28 days of moist curing were tested. For each mix design, the mean value of test results for three specimens is considered as the final test result.

The ingredients of RCC are similar to those of normal concrete. In this research, the RCC mix was composed of Portland cement, coarse aggregates (gravel), sand, filler (fine sand) and water with different water-cement ratios. A summary of the concrete mix designs are presented in Table 1. The mix designs of the three types $\mathrm{A}, \mathrm{B}$ and $\mathrm{C}$ are quite similar but with different weights of fibers.

TABLE I. SuMmary OF THE ROLLER COMPACTED CONCRETE MIX DESIGNS

\begin{tabular}{|c|c|c|c|c|c|c|c|}
\hline $\begin{array}{l}\text { Mix } \\
\text { No. }\end{array}$ & $\begin{array}{l}\text { MSA } \\
(\mathbf{m m})\end{array}$ & $\begin{array}{c}\text { Cement } \\
(\mathrm{kg})\end{array}$ & $\begin{array}{c}\text { Water } \\
\text { (kg) }\end{array}$ & $\begin{array}{c}\begin{array}{c}\text { Filler } \\
(\mathbf{k g})\end{array} \\
\end{array}$ & $\begin{array}{c}\text { Sand } \\
(\mathrm{kg})\end{array}$ & $\begin{array}{c}\text { Fine } \\
\text { Gravel } \\
\text { (kg) }\end{array}$ & $\begin{array}{c}\text { Coarse } \\
\text { Gravel } \\
\text { (kg) }\end{array}$ \\
\hline 1 & \multirow{4}{*}{12.5} & 192 & 118 & 280 & 701 & 801 & 0 \\
\hline 2 & & 235 & 122 & 280 & 701 & 801 & 0 \\
\hline 3 & & 281 & 106 & 280 & 701 & 801 & 0 \\
\hline 4 & & 329 & 110 & 280 & 701 & 801 & 0 \\
\hline 5 & \multirow{4}{*}{19} & 192 & 88 & 276 & 736 & 407 & 353 \\
\hline 6 & & 235 & 101 & 276 & 736 & 407 & 353 \\
\hline 7 & & 281 & 114 & 276 & 736 & 407 & 353 \\
\hline 8 & & 329 & 118 & 276 & 736 & 407 & 353 \\
\hline 9 & \multirow{4}{*}{25} & 192 & 148 & 183 & 824 & 353 & 405 \\
\hline 10 & & 235 & 152 & 183 & 824 & 353 & 405 \\
\hline 11 & & 281 & 176 & 183 & 824 & 353 & 405 \\
\hline 12 & & 329 & 171 & 183 & 824 & 353 & 405 \\
\hline
\end{tabular}

\section{Ultrasonic Pulse Velocity Test}

In this study, the ultrasonic pulse velocity (UPV) instrument is used to determine the P-wave velocity of the concrete. The standard method of ultrasonic test is described in ASTM C-597 [12]. The apparatus is portable and easy to use and includes a processor unit that sends and receives ultrasonic pulses and measures the time between the two operations (sending and receiving). It also has two probes connected to two cables, which perform the transmission of ultrasonic pulses. Fig. 1 illustrates a UPV device.

In a comparative manner, a higher velocity is obtained when concrete is of better quality in terms of density, uniformity, compressive strength, etc. As shown in Fig. 2, there are three types of arrangements for probes in a UPV test: direct transmission, semi-direct transmission and indirect or surface transmission. In this study, for compliance testing in the laboratory and in the field, only the indirect transmission is considered. Each cubic sample was tested at various points and at different sides. The mean value of total measurements on each sample is considered as velocity of the P-wave for that sample. The average of the test results of the three specimens is considered as the final result for each mix design.

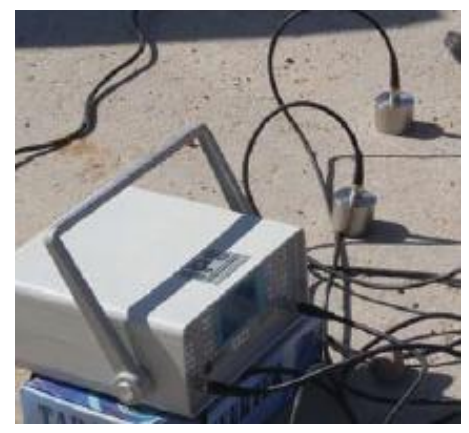

Figure 1. Ultrasonic pulse velocity device

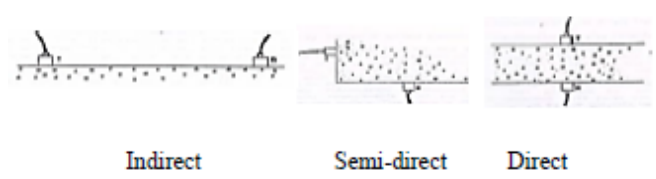

Figure 2. Types of arrangements of probes in a UPV test

\section{Schmidt Hammer Test}

Schmidt hammer, also known as rebound hammer, is a device to measure the surface hardness or strength of concrete or rock. It works based on the principle that the rebound of an elastic mass depends on the hardness of the surface against which the mass impinges. The standard method of this test is described in ASTM C-805 [13]. This NDT technique is an indirect method because instead of the compressive strength, a rebound value is measured. There is little theoretical correlation between the strength of concrete and the rebound number of the hammer. However, empirical correlations have been established between strength properties and the rebound number. The method is fast, inexpensive and easy to perform and does not damage the concrete like in destructive methods. Tests can be done insitu on the whole surface of a concrete structure; hence, the quality of the entire structure is tested rather than only the quality of a few specimens crushed with destructive methods. In general, Schmidt hammer test is useful in assessing concrete uniformity and comparing one concrete against another. Fig. 3 shows a Schmidt hammer device.

In this study, each cubic specimen was tested at various points and at different sides. For each specimen 9 tests were performed and the average of these measurements is considered as the result for that specimen. The mean value of the test results of the three specimens is considered as the final result for each mix design.

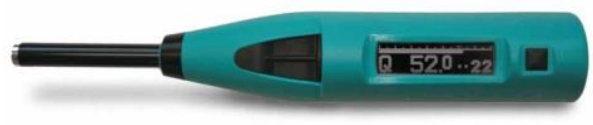

Figure 3. Schmidt hammer device 


\section{TEST RESULTS}

In this experiment, three different tests were performed on each specimen include two nondestructive testes and one destructive. As described in the previous sections, at the beginning, UPV and Schmidt hammer tests were carried out on each cubic sample and then each cube was broken by concrete compression test machine. A summary of tests results is shown in tables 2 to 4 . The presented values in the third column of these tables are outcomes of destructive tests using compression test machine and the values in the fourth and fifth columns are results of nondestructive tests using UPV and Schmidt hammer techniques, respectively. These tables show that the difference in the compression strength between the conventional RCC (Type A) and fiber RCC (types B and C) is about 5-15\%. In other words, the effect of polypropylene fibers on compressive strength of RCC is not very significant. In most cases, however, an addition of polypropylene fibers has been used to improve some mechanical properties of concrete, control plastic shrinkage and cracks and reduce pavement thickness.

TABLE II. RESUltS OF PERFORMED TESTS ON TyPE A CONCRETE (WITHOUT FIBER)

\begin{tabular}{|c|c|c|c|c|}
\hline Mix No. & $\begin{array}{l}\text { MSA } \\
(\mathbf{m m})\end{array}$ & $\begin{array}{c}\mathbf{f}_{\mathrm{c}} \\
(\mathbf{M P a})\end{array}$ & $\begin{array}{c}\mathbf{v}_{\mathrm{c}} \\
(\mathrm{km} / \mathrm{S})\end{array}$ & Rebound \\
\hline A1 & \multirow{4}{*}{12.5} & 7.82 & 3.68 & 10.07 \\
\hline $\mathrm{A} 2$ & & 12.59 & 3.75 & 10.30 \\
\hline A3 & & 17.56 & 3.87 & 11.70 \\
\hline A4 & & 23.28 & 3.97 & 13.52 \\
\hline A5 & \multirow{4}{*}{19} & 15.04 & 4.07 & 11.37 \\
\hline A6 & & 15.73 & 4.09 & 10.52 \\
\hline A7 & & 21.06 & 4.14 & 13.07 \\
\hline A8 & & 28.71 & 4.14 & 14.67 \\
\hline A9 & \multirow{4}{*}{25} & 18.05 & 3.91 & 10.96 \\
\hline A10 & & 22.80 & 3.94 & 12.37 \\
\hline A11 & & 28.42 & 3.96 & 13.85 \\
\hline A12 & & 34.07 & 4.03 & 15.85 \\
\hline
\end{tabular}

TABLE III. RESUltS OF PERFORMED TESTS ON TYPE B CONCRETE (WITH 1 KG/M3 PP FIBER)

\begin{tabular}{|c|c|c|c|c|}
\hline Mix No. & $\begin{array}{l}\text { MSA } \\
(\mathrm{mm})\end{array}$ & $\begin{array}{c}\mathbf{f}_{\mathbf{c}} \\
(\mathbf{M P a})\end{array}$ & $\begin{array}{c}\mathbf{v}_{\mathrm{c}} \\
(\mathrm{km} / \mathrm{S})\end{array}$ & Rebound \\
\hline B1 & \multirow{4}{*}{12.5} & 8.34 & 4.20 & 10.04 \\
\hline B2 & & 15.79 & 4.20 & 11.00 \\
\hline B3 & & 17.79 & 4.14 & 11.19 \\
\hline B4 & & 24.00 & 4.05 & 11.11 \\
\hline B5 & \multirow{4}{*}{19} & 16.74 & 4.12 & 11.22 \\
\hline B6 & & 17.07 & 4.18 & 12.22 \\
\hline B7 & & 23.28 & 4.22 & 13.59 \\
\hline B8 & & 29.043 & 4.21 & 12.19 \\
\hline B9 & \multirow{4}{*}{25} & 18.93 & 4.06 & 12.48 \\
\hline B10 & & 23.94 & 4.05 & 12.76 \\
\hline B11 & & 33.81 & 4.05 & 13.07 \\
\hline B12 & & 36.07 & 4.08 & 15.96 \\
\hline
\end{tabular}

By studying the results of the tests, it can be concluded that by increasing the nominal maximum size of aggregates, the compressive strength of RCC increases significantly which is also quiet similar for fiber RCC. Results of UPV tests show that increasing the compressive strength increases the velocity of P-wave. Also, results of Schmidt hammer tests show that by increasing the compressive strength, the rebound value of RCC usually increases.

TABLE IV. RESUlTS OF PERFORMED TESTS ON TYPE C CONCRETE (WITH 2 KG/M3 PP FIBER)

\begin{tabular}{|c|c|c|c|c|}
\hline Mix No. & $\begin{array}{l}\text { MSA } \\
(\mathrm{mm})\end{array}$ & $\begin{array}{c}\mathbf{f}_{\mathrm{c}} \\
(\mathrm{MPa})\end{array}$ & $\begin{array}{c}\mathbf{v}_{\mathbf{c}} \\
(\mathrm{km} / \mathrm{S})\end{array}$ & Rebound \\
\hline $\mathrm{C} 1$ & \multirow{4}{*}{12.5} & 13.93 & 4.25 & 11.70 \\
\hline $\mathrm{C} 2$ & & 16.84 & 4.34 & 12.04 \\
\hline C3 & & 21.58 & 4.39 & 12.33 \\
\hline $\mathrm{C} 4$ & & 24.65 & 4.22 & 13.67 \\
\hline $\mathrm{C} 5$ & \multirow{4}{*}{19} & 17.89 & 4.43 & 12.26 \\
\hline C6 & & 20.60 & 4.42 & 12.3 \\
\hline C7 & & 25.21 & 4.53 & 13.44 \\
\hline C8 & & 31.19 & 4.21 & 14.81 \\
\hline C9 & \multirow{4}{*}{25} & 19.49 & 4.32 & 12.81 \\
\hline $\mathrm{C} 10$ & & 24.30 & 4.35 & 13.92 \\
\hline C11 & & 33.52 & 4.46 & 14.96 \\
\hline C12 & & 37.92 & 4.49 & 15.99 \\
\hline
\end{tabular}

\section{PREDICTION OF CONCRETE COMPRESSIVE STRENGTH USING THE ARTIFICIAL INTELLIGENCE APPROACH}

There is no exact relation between concrete compressive strength and P-wave velocity or rebound value. However, empirical relationships can be introduced by simultaneously measuring the P-wave velocity or rebound value and the compressive strength of concrete. As an example, the least squares method can be used to fit the proper diagram between experimental test results. The best curve is the one from which the sum of squared distances of the experimental points is minimal. In addition to curve fitting techniques such as the least squares method, the Artificial Intelligence (AI) approach can be used to estimate compressive strengths of concrete. Artificial intelligence is a branch of computer science, renders the computers or machines as intelligent as the human mind. Conventional methods for curve fitting, modeling and optimizing complex systems require huge amounts of computing resources. However, artificialintelligence-based solutions can often give good alternatives for efficiently solving problems in civil engineering. Many tools can be used in AI, including fuzzy logic, neural networks and evolutionary algorithms (such as genetic algorithm and gene expression programing).

In this research, the Gene Expression Programming (GEP) method has been used to predict the compressive strength of RCC. In this method, computer programs are complex tree structures that learn and adapt by changing their sizes, shapes, and composition, much like a living organism. GEP belongs to the family of evolutionary algorithms and is closely similar to genetic algorithms and genetic programming. This method uses linear chromosomes composed of genes structurally organized in a head and a tail. The chromosomes operate as a genome and are subjected to modification by means of mutation, root transposition, gene transposition, gene recombination, and one- and two-point recombination [14]. A correlation coefficient (R) can be used to specify the accuracy of the obtained relationships and their compatibility with test results. $\mathrm{R}$ being close to 0 means that there is little 
relation between the variables and when it is close to 1 there is strong relation between the variables. The R-squared (R2) method or coefficient of determination may be used instead of the correlation coefficient (R) to indicate the percentage of variables explained by a proposed model (fitted curve).

Since the effect of polypropylene fibers on compressive strength of RCC is almost negligible, for all the three types of concrete in this study one single relationship is proposed.

In the first step, the relation between compressive strength of RCC and P-wave velocity was determined using GEP. Equation (1) is obtained for prediction of the compressive strength of RCC based on P-wave velocity data obtained from ultrasonic pulse velocity test. In this equation, the compressive strength of the 28-day concrete cubic sample (fC) is in MPa, and P-wave velocity (vc) is in $\mathrm{km} / \mathrm{Sec}$. The coefficient of determination for this equation is $\mathrm{R} 2=0.73$, that indicates that the accuracy of the relation is relatively good. This formula enables one to predict concrete strength of existing RCC pavement whose concrete properties and mix design is not available.

$$
f_{c}=30.2 v_{c}-103
$$

In the second step, the relation between compressive strength of RCC and rebound value was calculated using GEP. Equation (2) is obtained based on the rebound value (Re) obtained from Schmidt hammer test. In this relationship, the compressive strength of the 28-day concrete cubic sample (fC) is in MPa. The R-square for this equation is 0.71 that shows a good estimation compared to other researchers' works.

$$
f_{c}=3.87 \mathrm{Re}-27.3
$$

Equations (1) and (2) are obtained for prediction of the compressive strength of RCC based only on P-wave velocity or rebound value data. Finally, to increase the accuracy, the results of the two NDT techniques can be combined. Equation (3) is obtained for prediction of the compressive strength of RCC based on P-wave velocity (vc) and rebound value (Re), simultaneously. In this relationship, the compressive strength of the 28-day concrete cubic sample (fC) is in $\mathrm{MPa}$ and $\mathrm{vc}$ is in $\mathrm{km} / \mathrm{Sec}$. The R-square for this equation is 0.80 that is greater than those in (1) and (2).

$$
f_{c}=0.136 \mathrm{Re}^{2}-\frac{2.59}{v_{c}(\operatorname{Re}-9.93)}
$$

All equations above have good accuracy and are simple, applicable and easy to use. However, GEP can provide more accurate relations with better R-squares, but having more complicated formulae which are not as easy to use.

Results of this research show that employing combined NDT techniques provides more accurate estimation of compressive strength of concretes compared with using only one NDT technique.
It should be noted that to convert the compressive strength of the cube specimens to compressive strength of the cylinder specimens, the coefficient of 0.833 can be used.

\section{CONCLUSIONS}

In this research, two different nondestructive techniques were used to estimate the compressive strength of the conventional and fiber roller compacted concretes. The first technique was ultrasonic pulse velocity test and the second was Schmidt hammer test. Through artificial intelligence concepts and using gene expression programming, some applicable formulae were proposed for prediction of concrete strength. A summary of this research results is as follows:

- For both conventional and fiber RCC, increasing the maximum size of aggregates leads to significant increase of the compressive strength.

- Increasing the compressive strength of concrete results in increase of P-wave velocity.

- Increasing the compressive strength of concrete usually increases the rebound value of RCC.

- Polypropylene fibers have insignificant effect on compressive strength of RCC and increase compressive strength of RCC only about 5-15\%.

- To predict the compressive strength of RCC using the results of NDT, the method of artificial intelligence (GEP) yields high efficiency and accuracy.

- For an existing RCC with unknown mix design, using the proposed formulae to estimate the strength of concrete can lead to relatively accurate results.

- All proposed relationships have simple and practical forms and can be used easily to estimate the compressive strength of existing RCCs. To do this, it is only needed to carry out some nondestructive testes such as ultrasonic or Schmidt hammer on existing RCC.

- The results prove the ability and efficiency of the combination of two different NDT methods (UPV and Schmidt hammer) to estimate the compressive strength of the existing RCC.

\section{REFERENCES}

[1] S. K. Sahu and K. K. Jain, "Assessment of concrete quality from pulse velocity tests, non-destructive testing," Civil Engineering Review, 1998, pp.43 - 45.

[2] D. M. McCann and M. C. Forde, "Review of NDT methods in the assessment of concrete and masonry structures," NDT Int., 34(2), 2001,pp. 71-84.

[3] R. S. Carcano and E. I. Moreno, "Evaluation of concrete made with crushed limestone aggregate based on ultrasonic pulse velocity," Construction and Building Materials, 22, 2008, pp.1225-1231.

[4] K. Szilágyi, A. Borosnyói, and I. Zsigovics, "Rebound surface hardness of concrete: Introduction of an empirical constitutive model," Construction and Building Materials, vol. 25, 2011, pp.24802487.

[5] D. Breysse, "Nondestructive evaluation of concrete strength: An historical review and a new perspective by combining NDT methods", Construction and Building Materials, vol.33, 2012, pp.139-163. 
[6] M. A. Kewalramani and R. Gupta, "Concrete compressive strength prediction using pulse velocity through artificial neural networks," Elsevier, Automation in Construction, 15, 2006.

[7] G. Trtnik, F. Kavaĉiĉ, and G. Turk, "Prediction of concrete strength using ultrasonic pulse velocity and artificial neural networks," Elsevier, Ultrasonic, 49, 2009.

[8] S. M. Mousavi, P. Aminian, A. H. Gandomi, A. H. Alavi, and H. Bolandi, "A new predictive model for compressive strength of HPC using gene expression programming," Advances in Engineering Software, 45, 2012, pp. 105-114.

[9] K. Sobhan and M. Mashnad, "Roller-compacted fiber concrete pavement foundation with recycled aggregate and waste plastics," Transportation Research Record, vol. 1775, 2001, pp.53-63.
[10] S. Tangtermsirikul, T. Kaewkhluab, and P. Jitvutikrai, "A compressive strength model for roller-compacted concrete with fly ash," Magazine of Concrete Research, 56(1), 2004, pp. 35-44.

[11] L. Courard, F. Michel, and P. Delhez, "Use of concrete road recycled aggregates for roller compacted concrete," Construction and Building Materials, 24(3), 2010, pp. 390-395.

[12] ASTM C-597, "Standard test method for pulse velocity through concrete", 2009.

[13] ASTM C805 / C805M-13a, "Standard test method for rebound number of hardened concrete", 2013.

[14] C. Ferreira, "Gene expression programming: a new adaptive algorithm for solving problems, " Complex Systems, 13(2), 2001, pp.87-129. 